\title{
Levodopa Activates Apoptosis Signaling Kinase 1 (ASK1) and Promotes Apoptosis in a Neuronal Model: Implications for the Treatment of Parkinson's Disease
}

\author{
Elizabeth A. Sabens ${ }^{\ddagger, \#}$, Kelly M. Steller ${ }^{\ddagger} \S$, and John J. Mieyal ${ }^{\ddagger, \S, *}$ \\ ¥Department of Pharmacology, Case Western Reserve University, School of Medicine 2109 \\ Adelbert Rd., Cleveland, Ohio 44106-4965 \\ $\S$ Louis B. Stokes Veterans Affairs Medical Research Center, 10701 East Blvd., Cleveland, Ohio \\ 44106
}

\section{Abstract}

Oxidative stress is implicated in the etiology of Parkinson's disease (PD), the second most common neurodegenerative disease. PD is treated with chronic administration of L-3,4dihydroxyphenylalanine (Levodopa, L-DOPA), and typically increasing doses are used during progression of the disease. Paradoxically L-DOPA is a pro-oxidant and induces cell death in cellular models of PD through disruption of sulfhydryl homeostasis involving loss of the thioldisulfide oxidoreductase functions of the glutaredoxin (Grx1) and thioredoxin (Trx1) enzyme systems (Sabens et al. 2010). Considering this loss of both Grx1 and Trx1 activities upon LDOPA treatment, we sought to elucidate the mechanism(s) of L-DOPA induced apoptosis. In other contexts both the NFKB (nuclear factor $\mathrm{\kappa B}$ ) pathway and the ASK1 (apoptosis signaling kinase 1) pathway have been shown to be regulated by both Grx1 and Trx1, and both pathways have been implicated in cell death signaling in model systems of PD. Moreover, mixed lineage kinase (MLK) has been considered as a potential therapeutic target for PD. Using SHSY5Y cells as model dopaminergic neurons we found that NFkB activity was not altered by L-DOPA treatment, and the selective MLK inhibitor (CEP-1347) did not protect the cells from L-DOPA. In contrast, ASK1 was activated with L-DOPA treatment as indicated by phosphorylation of its downstream mitogen activated protein kinases (MAPK), p38 and JNK. Chemical inhibition of either $\mathrm{p} 38$ or JNK provided protection from L-DOPA induced apoptosis. Moreover, direct knockdown of ASK1 protected from L-DOPA induced neuronal cell death. These results identify ASK1 as the main pro-apoptotic pathway activated in response to L-DOPA treatment, implicating it as a potential target for adjunct therapy in PD.

\section{Introduction}

Parkinson's disease (PD), the second most common neurodegenerative disease, affects primarily catecholaminergic neurons in the substantia nigra of the brain (1). PD is linked to both genetic and environmental factors such as pesticides (2). Pathogenesis of PD, involving oxidative stress, mitochondrial dysfunction, and protein aggregation, manifests itself through loss of dopaminergic neurons resulting in a constellation of movement disorders.

\footnotetext{
* To whom correspondence should be addressed. Dr. John J. Mieyal, Department of Pharmacology, Case Western Reserve University, School of Medicine, 2109 Adelbert Rd., WRT300-9, and the Louis Stokes Cleveland Veterans Affairs Medical Research Center, Cleveland, OH 44106-4965 Telephone: (216) 368-3383. Fax: (216) 368-8887.jjm5 @ cwru.edu.

\#Studies completed in partial fulfillment of the requirements or the Ph.D. degree, Case Western Reserve University Author Contributions: Sabens and Mieyal participated in research design and writing of the manuscript. Sabens and Steller conducted the experiments.
} 
Many reports have attributed loss of dopaminergic neurons to the oxidative stress associated with increased dopamine turnover, deficient glutathione content, and increased iron content in the substantia nigra (2-4). Thus, the surviving neurons are susceptible to further oxidative challenge. Paradoxically, L-DOPA, the primary agent for therapy of PD, itself is a prooxidant, and it is typically used in increasing doses as the disease progresses. Thus, L-DOPA may exacerbate an already compromised cellular system and aggravate a condition that it meant to alleviate. Indeed, exposure of catecholaminergic cells (PC12; SHSY5Y) in culture to increasing concentrations of L-DOPA has been reported to cause cell death $(5 ; 6)$; however, the primary controlling factors leading to the L-DOPA induced cell death have not been elucidated. L-DOPA is metabolized to dopamine, which is autooxized and re-reduced, thereby contributing to oxidative stress by generating superoxide and hydrogen peroxide. The oxidation product dopaquinone also can adduct cysteine residues on proteins irreversibly, forming S-cysteinyl dopamine adducts, altering protein function (2;6). Previous studies of the oxidant sensitivity of catecholaminergic cells in culture have employed dopamine-related toxins, such as 6-hydroxydopamine (6-OHDA) and 3,4dihydroxyphenylacetic acid (DOPAC); and they have identified which apoptotic signaling pathways might be activated, depending on the nature and intensity of the oxidant challenge (7-11). Such agents were chosen because of their propensity to promote oxidative stress. For example, 6-OHDA produces four main oxidation products that differ from those of dopamine and are implicated in cytotoxicity (12). L-DOPA would not be expected to be as active nor to promote cytotoxicity via the same molecular mechanism as 6-OHDA. Therefore, to anticipate improved therapy for PD, the current study was focused on the mechanism(s) by which the primary therapeutic agent L-DOPA promotes cell death. Identifying key apoptotic control points activated by L-DOPA would reveal potential therapeutic targets for minimizing toxicity to the neurons. Oxidative stress has the potential to disrupt sulfhydryl homeostasis in cells and alter the functions of proteins with reactive cysteine residues. This condition is exacerbated if one or both of the glutaredoxin or thioredoxin enzyme systems is impaired, because they are responsible for reversing proteinS-glutathionylation and inter- or intramolecular disulfides, respectively (13). We recently discovered that L-DOPA treatment of SHSY5Y neuronal cells leads to loss of activity of both Grx1 and Trx1, apparently through different mechanisms, concomitant with apoptosis (6). Since the cellular mechanism(s) of the pro-apoptotic response of L-DOPA is currently unknown, we investigated pathways involved in cell fate that have been previously shown to be regulated by both Grx1 and Trx1.

In a variety of contexts, the NFkB pathway has been shown to be regulated by both Trx (reviewed in $(14 ; 15))$ and Grx $(16)$, where redox regulation occurs at several control points in the signaling pathway. Furthermore, upregulation of $\mathrm{NF \kappa B}$ was noted in post mortem brain samples from PD patients, and model studies of mouse brain where NFKB was inhibited suggested it might be pro-apoptotic (17). Typically activation of NFKB is considered to be a pro-survival mechanism in cells; however previous studies, despite using the same cell line (PC12), gave disparate results suggesting either a pro-apoptotic $(11 ; 18)$ or a pro-survival (19) function of the transcription factor. These different outcomes for NFkB activation might reflect different responses dependent on the type or duration of the chemical insult. Hence it could not be predicted how L-DOPA would affect NFKB activity in SHSY5Y model neurons.

ASK1, a MAPKKK (mitogen activated protein kinase kinase kinase), is a central mediator of a prominent pathway to apoptosis, and it is subject to multiple modes of redox regulation implicating both Grx1 and Trx1 (20). Moreover, ASK1 activation has been reported in several animal and cellular models of PD (10) (9), (21), (22) (23). Activation of ASK1 results in phosphorylation of downstream substrates such as p38-MAPK or c-Jun N terminal 
kinase (JNK), both implicated in propagation of apoptosis (10;24-27). In addition, mixed lineage kinase (MLK), also a MAPKKK, can mediate apoptosis through p38 and JNK.

In this study, we examined the effect of L-DOPA treatment on the NFkB and ASK1 pathways in SHSY5Y neurons, a typical model for dopaminergic neurons (see Experimental Procedures). Little effect of L-DOPA was seen on transcriptional activity of NFKB. In contrast, ASK1 was activated in SHSY5Y neurons in an L-DOPA dose-dependent manner, leading to phosphorylation of p38 and JNK. Moreover, inhibition of p38 and JNK, and selective knockdown of ASK1 protected the SHSY5Y neurons from L-DOPA induced cell death, identifying ASK1 as the primary mediator of apoptosis. Furthermore, we pretreated the cells with a selective inhibitor of MLK, the other MAPKKK which can mediate apoptosis through p38 and JNK, and observed no protection from L-DOPA induced apoptosis.

\section{Experimental Procedures}

\section{Materials}

SHSY5Y cells were obtained from ATCC (Manassas, VA). Hoechst 33342 trihydrochloride, lipofectamine 2000, and cell culture reagents were obtained from Invitrogen. The selective inhibitors, SB202190 targeted to p38 and SP600125 targeted to JNK, were obtained from Sigma. ASK1 antibody, F-9 (mouse anti-human for immunoblotting), was purchased from Santa Cruz Biotechnologies. Anti-actin antibody (clone AC74) was purchased from Sigma. Antibodies for western blot detection of the MAPKs were kind gifts from Dr. Laura Nagy (Cleveland Clinic Foundation) and were obtained as follows: total JNK (Santa Cruz), phospho-JNK (Thr 183, Tyr 185) (Cell Signaling), total p38 (Santa Cruz Biotechnologies) and phospho-p38 (Thr 180, Tyr 182) (Promega). ASK1-targeted and nontargeted control SMARTPool siRNA samples were purchased from Dharmacon. All other chemicals were purchased from Sigma unless otherwise specified.

Cell Culture-SHSY5Y cells from ATCC were isolated from human bone marrow neuroblastoma and were derived 3 times to obtain homogeneous dopamineric-like neuronal cells. This cell line displays typical dompamineric characteristics, including expression of tyrosine hydroxylase, dopamine transporter and receptor, and monoamine oxidase A \& B (28-30). Throughout this document for simplicity these cells are referred to as "SHSY5Y neurons." The SHSY5Y neurons were maintained under an atmosphere of air with $5 \% \mathrm{CO}_{2}$ at $37^{\circ} \mathrm{C}$. The medium was comprised of a 1:1 mixture of MEM and Hams F12 media (Mediatech, Cell Gro), containing $0.01 \mathrm{mM}$ Na pyruvate, $1 \mu \mathrm{M}$ nonessential amino acids and $10 \%$ certified fetal bovine serum. Cells were plated in $100 \mathrm{~mm}$ dishes, 96-well plates (for assay with MTT (3-[4,5-dimethylthiazol-2-yl]-2,5-diphenyl tetrazolium bromide)) or 6well plates (for Hoechst staining) and allowed to come to $\sim 75 \%$ confluency prior to treatment.

Treatments of cells in culture-L-DOPA was added to cell culture media for $24 \mathrm{hr}$ at concentrations ranging from 0 to $250 \mu \mathrm{M}$. For MAPK inhibitor studies, SB202190 (p38 inhibitor) or SP600125 (JNK1,2,3 inhibitor) were applied to cells 30 min before L-DOPA was added to the medium. MLK inhibitor, CEP-1347, was the generous gift of Cephalon, Inc. Concentrations of CEP-1347 ranged from 0-500nM and were applied 30 min prior to LDOPA treatment. Cells were analyzed $24 \mathrm{hr}$ post L-DOPA treatment.

Cell Death Assays-To detect chromatin condensation indicative of apoptosis, Hoechst 33342 trihydrochloride was added to the medium of each set of cells to a final concentration of $10 \mu \mathrm{M}$ for $10 \mathrm{~min}$ at $37^{\circ} \mathrm{C}$, according to manufacturer's protocol. Cells were counted on a 
Leica microscope with a DAPI fluorescent filter. Quantitative analysis of Hoechst staining of the cells was done in a blinded fashion with respect to treatment conditions.

Caspase 3 activity was measured spectrophotometrically. Cells were treated with L-DOPA for $8 \mathrm{hr}$ and then lysed in 1\% CHAPS, $150 \mathrm{mM} \mathrm{NaCl}, 10 \mathrm{mM}$ HEPES, $10 \mathrm{mM}$ EDTA, 1× Sigma protease inihibitor cocktail pH 7.4. $100 \mu \mathrm{g}$ of cell lysate was incubated at $37^{\circ} \mathrm{C}$ for $1 \mathrm{hr}$ in ICE buffer (50 mM Tris-HCl pH 7.2, $100 \mathrm{mM} \mathrm{KCl,} 10 \%$ sucrose, $0.1 \%$ CHAPS, and $5 \mathrm{mM}$ DTT) with $0.1 \mathrm{mM}$ caspase substrate (Calbiochem). Fluorescence was measured at excitation wavelength $360 \mathrm{~nm}$ and emission wavelength of $460 \mathrm{~nm}$ (Novastar).

Cell Viability-Cell viability was measured according to reactivity of MTT according to manufacturer's protocol. MTT at a final concentration of $0.5 \mathrm{mg} / \mathrm{mL}$ was placed on the cells for $3 \mathrm{hr}$ at $37^{\circ} \mathrm{C}$. Medium was removed and replaced with MTT solubilization solution $(0.1 \mathrm{~N}$ $\mathrm{HCl}$ in anhydrous isopropanol and $10 \%$ Triton $\mathrm{X}$ ). Culture dishes were shaken at room temperature for $1 \mathrm{hr}$ to solubilize the formazan crystals before measuring the absorbance at $570 \mathrm{~nm}$ for each well. Nonspecific absorbance at $690 \mathrm{~nm}$ was subtracted.

NFkB Luciferase Activity-SHSY5Y cells were plated to $60 \%$ confluence and transfected for $12 \mathrm{hr}$ with $1 \mu \mathrm{g}$ of 5x NFKB luciferase plasmid (Stratagene, La Jolla, CA) and $0.1 \mu \mathrm{g}$ of Renilla plasmid (Promega, Madison, WI) for $12 \mathrm{hr}$, according to the Lipofectamine (Invitrogen) reagent protocol. Transfection medium was then changed to replete medium and the cells incubated for an additional $12 \mathrm{hr}$ at $37^{\circ} \mathrm{C}$. Cells were then treated with LDOPA for $24 \mathrm{hr}$. Cells were harvested and lysed in passive lysis buffer and assayed using the Dual-Luciferase assay system (Promega), measuring emission with a luminometer (SOFTmax PROsoftware, Molecular Devices, Sunnyvale, CA). NFאB activity is expressed as firefly luciferase dependent luminescence relative to Renilla luciferase dependent luminescence.

Detection of Phosphorylated Proteins-SHSY5Y cells were lysed in RIPA buffer containing $150 \mathrm{mM} \mathrm{NaCl}, 10 \mathrm{mM}$ EDTA, $1 \%$ NP40, 0.5\% deoxycholic acid, 0.1\% SDS, and $50 \mathrm{mM}$ Tris, $\mathrm{pH} 7.5$, along with Sigma protease inhibitor cocktail. Protein determinations were performed using the bicinhoninic acid (BCA) assay (Pierce, Rockford, IL) For western blots, 50-100 $\mu \mathrm{g}$ of total protein was run on a 10\% SDS-PAGE gel before transfer to a PVDF membrane. Membranes were blocked with 3\% BSA solution and probed overnight with the appropriate phospho-protein antibody in a 1\% BSA solution. Blots were developed using enhanced chemiluminescent substrate (Pierce). Blots were subsequently stripped with stripping buffer (20\% SDS (w/v), $56 \mathrm{mM}$ Tris HCl, $0.1 \mathrm{M} \mathrm{BME,} 1 \mathrm{mM}$ DTT) for $30 \mathrm{~min}$ at $60^{\circ} \mathrm{C}$ and reprobed for total content of the target proteins in a similar fashion. Quantification of blots was performed on digitized gel scans with BioRad Quantity One Software.

Estimates of phosphorylated proteins are presented as densitometric ratios, normalized to the corresponding total protein content.

Knockdown of ASK1-SmartPOOL siRNA (Dharmacon) was used to knockdown ASK1. $200 \mathrm{nM}$ siRNA was transfected into cells with Lipofectamine 2000 (Invitrogen) according to manufacturer's instructions. Cells were incubated with siRNA for $6 \mathrm{hr}$ in OptiMEM. Medium was changed to serum replete medium. Cells were treated with LDOPA or vehicle $24 \mathrm{hr}$ after transfection with siRNA. Cell death was measured $24 \mathrm{hr}$ post L-DOPA treatment (48 hr post transfection with siRNA). Western blot analysis was used to confirm that ASK1 remained knocked down for the duration of L-DOPA treatment.

Statistical Methods-Statistical analysis was performed on all data using a two tailed Student's t-test. Comparisons were considered to be significantly different when $\mathrm{p}$ values were less than or equal to 0.05 . 


\section{Results}

\section{L-DOPA Treatment of SHSY5Y Cells Does Not Alter NFkB Activity}

Previously L-DOPA induced apoptotic death of PC12 catecholaminergic cells was reported to be due to increased oxidative stress (5). We recently found L-DOPA treatment of SHSY5Y neurons disrupts sulfhydryl homeostasis by deactivating the Grx1 and Trx 1 systems, leading to apoptotic cell death (6). To further elucidate the mechanism of the LDOPA induced apoptosis, we examined signaling pathways that have been implicated in neuronal cell death, and known to be regulated by both Trx 1 and Grx 1 in other contexts.

NFKB has been reported to be regulated by both Grx1 (16;31) and Trx1 (reviewed in (14)); however its role in mediating oxidant-induced death of catecholaminergic cells is ambiguous, as described above. Hence, we examined the transcriptional activity of NFKB by reporter gene assay in response to L-DOPA treatment of the SHSY5Y neurons. We found $\mathrm{NF \kappa B}$ transcriptional activity to be essentially unchanged over the range of L-DOPA concentrations that elicit marked increases in apoptosis (Figure 1). No change in NFKB activity was observed up to 24 hours after L-DOPA treatment, at which time approximately $60 \%$ of the cells at the highest L-DOPA concentration have condensed chromatin indicative of late apoptosis (6). These observations rule out consideration of the NFkB pathway as a contributor to L-DOPA induced apoptosis in the SHSY5Y neurons.

\section{L-DOPA Treatment Increases Phosphorylation of p38 and JNK, in SHSY5Y Neurons}

We then turned our attention to ASK1, another central intermediate involved in apoptosis signaling. ASK1 has been shown to be regulated by both the Grx1 (32) and Trx1 (33) systems in other contexts. Activation of ASK1 leads to phosphorylation of MAPKKs, MEK $3 / 6$ and 4/7, ultimately leading to phosphorylation of downstream MAPKs p38 and JNK. Activation of p38 and JNK through phosphorylation can result in a variety of responses, likely stimuli dependent, including cell growth, differentiation, cytokine production, and apoptosis(24-26;34). We found that L-DOPA treatment significantly increased phosphorylation of both p38 (Figures 2A) and JNK (Figure 2B). Phosphorylation of p38 appears to be approaching maximum at the drug concentrations tested whereas JNK phosphorylation progressed in a L-DOPA dose dependent manner (Figure 2C, 2D). This increased phosphorylation led us to examine whether these kinases might be mediators of LDOPA induced apoptotic cell death.

\section{Chemical Inhibition of Activated MAPKs, p38 and JNK, Protect from L-DOPA Induced Apoptosis}

We used chemical inhibitors to block the function of p38 and/or JNK. SB202190, a selective p38 inhibitor, was applied to cells in a concentration range $(0-10 \mu \mathrm{M})$ that has been reported to limit its inhibitory effect to $\mathrm{p} 38$ ( $\alpha$ and $\beta$ ). Initially, effects of the selective kinase inhibitors were assessed by the MTT viability assay. It was confirmed that the p38 inhibitor alone did not alter cell viability; however when pretreatment with the p38 inhibitor was followed by L-DOPA treatment, cell viability increased substantially compared to cells that were treated with L-DOPA alone (data not shown). Increased viability coincided with diminution in apoptotic cells, where a p38-inhibitor concentration dependent protection was observed (Figure 3A). Phase contrast images, to distinguish between dividing cells and dying cells, confirmed that cell division did not interfere with the assessment of apoptosis (data not shown). L-DOPA treatment increased apoptosis from $<10 \%$ to $>40 \%$. In the presence of $5 \mu \mathrm{M}$ p38 inhibitor, apoptosis was markedly diminished, indicating the importance of this mediator in L-DOPA induced apoptosis. 
Similarly, pretreatment with the pan JNK inhibitor SP600125 afforded protection from LDOPA according to the cell viability assay; and this effect was documented as a diminution of apoptosis (Figure 3B). L-DOPA induced apoptosis was markedly decreased by pretreatment with $10 \mu \mathrm{M}$ JNK inhibitor, but not to the control level. Doubling the dose (i.e. $20 \mu \mathrm{M}$ ) did not afford greater protection probably due to cytotoxicity of the drug. We interpret these results to mean that inhibition of JNK alone is not sufficient to protect from L-DOPA induced cell death, implicating the contribution of both p38 and JNK to mediating L-DOPA induced apoptosis.

Therefore to detect whether the inhibitors acted synergistically we tested coincident treatment with both inhibitors at concentrations of each below those which gave maximal protection separately. The inhibitors offered no protection when each was added separately at lower concentrations (p38 inhibitor at $2.5 \mu \mathrm{M}$ and JNK inhibitor at $5 \mu \mathrm{M}$, Figures 3A, $3 \mathrm{~B}$ ). In contrast, pretreatment with both inhibitors (each at $2.5 \mu \mathrm{M}$ ) resulted in decreased LDOPA induced apoptosis (figure 3C), consistent with synergistic action of the p38 and JNK MAPKs in mediating the apoptotic response to L-DOPA treatment.

\section{Knockdown of ASK1 Prevents L-DOPA induced apoptosis}

To determine whether ASK1 is the primary kinase responsible for activation of p38 and JNK and the apoptotic response to L-DOPA we selectively knocked down ASK1 in the SHSY5Y neurons. We treated the cells with ASK1-targeted siRNA or scrambled siRNA for $24 \mathrm{hr}$ and then further treated with L-DOPA for $24 \mathrm{hr}$. We confirmed that ASK1 levels were substantially diminished by the targeted siRNA at $24 \mathrm{hr}$ just prior to L-DOPA treatment (Figure 4A). Thus, ASK1 was knocked down 77\% compared to control cells. When these cells were treated with L-DOPA $(100 \mu \mathrm{M})$, the percent apoptosis relative to ASK1-replete cells was diminished to an extent proportional to the ASK1 knockdown (Figures 4A, 4B). Thus, normalizing the percent apoptosis to the extent of knockdown (Figure 4B, bars at the far right) gives a percent apoptosis essentially the same as untreated cells.

In separate experiments we used caspase activity as the measure of apoptosis to assess the relationship between knockdown of ASK1 and protection of the SHSY5Y neurons from LDOPA-induced cell death (Figure 5). In this case a different supply of targeted siRNA resulted in $\sim 44 \%$ knockdown of the ASK1 (Figure 5A with representative blot in inset). When these cells were treated with L-DOPA $(100 \mu \mathrm{M})$, the percent apoptosis relative to ASK1-replete cells was diminished to an extent comparable to the extent of ASK1 knockdown (Figures 5B). Normalizing the percent apoptosis to the extent of knockdown (Figure 5B, bars at the far right) again gives a percent apoptosis indistinguishable from untreated cells. Thus, by two measures of apoptosis diminution of ASK1 content protected the neuronal cells from L-DOPA in an extent of knockdown-dependent fashion.

Furthermore, we tested whether a selective inhibitor (CEP-1347) of mixed lineage kinase (MLK), another MAPKKK which can mediate apoptosis through p38 and JNK, would afford protection. Addition of CEP 1347 up to $250 \mathrm{nM}$ prior to L-DOPA treatment did not provide protection from apoptosis (Figure 6). The concentration range of CEP-1347 $(0-250 \mathrm{nM})$ shown here is comparable to that reported previously to provide maximum protection of SHSY5Y cells from MPP+ induced apoptosis (35). Together these results identify ASK1 as the primary MAPKKK responsible for L-DOPA induced apoptosis in the SHSY5Y neurons, also distinguishing the effects of L-DOPA and MPP+ (see Discussion).

\section{Discussion}

Since L-DOPA remains the most efficacious drug for symptomatic treatment of PD, understanding how it may promote cell death signaling within a cell culture model for 
neurons provides valuable insights for mitigating its potential neurotoxic side effects in therapy of Parkinson's disease. In our previous study we found that selective deactivation of the Grx and/or Trx enzyme systems is sufficient to induce apoptosis in SHSY5Y neurons, and treatment of these cells with L-DOPA impaired both systems (6). Hence, in this study we investigated signaling pathways (NFKB and ASK1) involved in cell fate that have been previously shown to be regulated by both Grx 1 and Trx 1 . Neither activation nor inactivation of NFkB was observed (Figure 1). Instead, the observations support a scenario whereby LDOPA initiates an apoptotic cascade through activation of the ASK1 pathway, causing phosphorylation of downstream p38 and JNK kinases (Figure 2). L-DOPA induced apoptosis was largely prevented by inhibition of these downstream kinases (Figure 3) or by knockdown of the ASK1 protein (Figures 4, 5). The complex interactive signaling pathways within the cell which control apoptosis provide many points of initiation of a death cascade (36). Hence it is remarkable that knockdown of ASK1 or inhibition of its downstream molecular targets essentially abolished L-DOPA induced apoptosis. In contrast, MLK, the other MAPKKK that has been linked to downstream phosphorylation of p38 and JNK in other cell types, does not appear to be involved in the L-DOPA induced apoptosis of the SHSY5Y neurons, because treatment with the selective MLK inhibitor CEP 1347 did not protect from L-DOPA apoptosis (Figure 6). This result is especially noteworthy because MLK had been identified previously as a potential therapeutic target for PD (see below). We tested an extensive range of concentrations of CEP 1347 (0-1000nM), far exceeding the IC50 values (20-80 nM) for the MLK1,2,3 enzymes in isolation or expressed in CHO cells (37). No protection was seen up to $250 \mathrm{nM}$ (Figure 6), the concentration range previously shown to provide maximum protection from MPP+ induced apoptosis of SHSY5Y cells (35). Although a trend toward protection ( $<20 \%$; not statistically significant) was observed at $500 \mathrm{nM}$ and $1000 \mathrm{nM} \mathrm{CEP} 1347$ (data not shown), we expect this may be due to non selective inhibition of other targets, including ASK1, because many other proteins are reported to be inhibited at $500 \mathrm{nM}$ CEP 1347 besides the MLKs (37).

L-DOPA induces an oxidative stress that may lead to direct alteration of ASK1 or to modification and inhibition of the various regulators of ASK1 (described below). Previous studies with the LNCaP prostate cell line showed that treatment of ASK1 with Nethylmalemide, a thiol modifying agent, activates ASK1 (38). In another study site-directed mutagenesis of Cys residues on ASK1 altered Trx1 binding and phosphorylation of JNK (39). Analogous phenomena might occur with L-DOPA treatment, where quinone adduction or other modifications of cysteine residues such as sulfenic acid formation and/or glutathionylation could lead to activation of ASK1. It is conceivable that such modifications may interfere with particular sites of phosphorylation of ASK1 which promote inactivation or lead to degradation $(40 ; 41)$.

ASK1 exists as a signalosome, binding many positive and negative regulating proteins. It is proposed that dissociation of negative regulators and/or association of positive regulators leads to activation of ASK1 (20). In other contexts several negative regulators of ASK1 have been reported to be oxidatively modified, which could lead to their dissociation from ASK1 and initiation of apoptosis. For example, heat shock proteins (HSP) 72 and 90 have been reported to regulate the oligomeric state of ASK1 and its associated activity (42;43). HSP72 is modified by 4-hydoxynonenal in hepatocytes leading to loss of ATPase function (44). Additionally, HSP90 is reported to be inactivated by S-nitrosylation in endothelial cells (45). Peroxiredoxin 1 binds at the N-terminus of ASK1 and prevents its activation (46). Prx1 was found to be inactivated in MN9D cells after treatment with pro-oxidant 6-hydroxydopamine (47) which induces apoptosis, possibly implicating Prx1 dissociation in ASK1 activation. DJ-1, which functions as an antioxidant, transcriptional co-activator, and molecular chaperone, has been implicated in PD in connection with naturally occurring mutations of the protein. DJ-1, when oxidized, is also implicated as a direct binding negative regulator of 
ASK1 (48;49), or DJ-1, when reduced, is reported to be an indirect negative regulator of ASK1 by binding to $\operatorname{Daxx}(50)$. The latter function was shown to be impaired when Grx1 was knocked down (50).

As described above, many potential ASK1-binding proteins are susceptible to oxidative modifications of their cysteine residues with concomitant loss of function. Thus, the central role of Grx1 and Trx 1 in thiol homeostasis links these enzymes systems broadly to regulation of ASK1 function. The L-DOPA induced activation of ASK1 and neuronal apoptosis reported in this study may therefore result from diminished Grx 1 and/or Trx 1 activity (6), preventing the cell from maintaining proper thiol status of ASK1 and/or associated proteins. Other examples of this type of relationship have been reported. For example, cadmium treatment leads to activation of ASK1 and its downstream MAPK, JNK (51), and cadmium inhibits the components of the Grx1 and Trx 1 systems (52).

Besides their regulation of various other effectors of ASK1 activity, Grx1 and Trx1 themselves have been identified as negative regulators of ASK1. Grx1 binds to the Cterminus (32) and Trx1 to the N-terminus (33) of ASK1, and each of them are dissociated upon oxidative modification (32;33). Thus, L-DOPA treatment could lead to apoptosis simply through release of modified Grx1 and Trx1 from ASK1 or via the impact of deactivation of these enzymes on the function of the other ASK1 effectors. Distinguishing among these possibilities is the object of future studies.

The oxidative stress imposed by administration of L-DOPA promotes apoptosis by activation of ASK1 through the p38 and JNK branch of its signal transduction pathway. Both p38 and JNK have been shown to be activated by oxidative stress in a number of other studies of cultured cells (53), animal models $(10 ; 10)$, and post mortem human brains $(54 ; 55)$. For example, increased phosphorylation of $\mathrm{p} 38$ was found in post mortem samples of cortical neurons from patients with Lewy body dementia or Alzheimer's disease compared to age matched controls (55). Knockout of JNK3, the main isoform expressed in brain, protects mice and/or cortical derived neurons from a variety of apoptotic insults including $\mathrm{A} \beta$ toxicity, oxygen deprivation, kainic acid treatment, and glucose deprivation (26). Inhibition of JNK3 might therefore prevent further loss of dopaminergic neurons in PD patients. Accordingly, agents purported to be targeted to the JNK3 activation pathway entered clinical trials. Unfortunately, progression of PD does not appear to be delayed in patients receiving CEP-1347, a so-called "JNK3 inhibitor" (56). However, as indicated above, this inhibitor targets the upstream kinase MLK (37), which has been shown in other contexts, including the MPTP model of PD (35), to initiate activation of JNK at the same level as ASK1. In contrast, the findings of the present study instead identify ASK1 as the major upstream kinase responsible for JNK activation in the context of L-DOPA treatment and suggest that L-DOPA treatment may promote apoptosis in the brains of PD patients through activation of ASK1. Hence, targeting ASK1 as an adjunct to treatment with LDOPA may be a more effective therapeutic approach.

\section{Acknowledgments}

The authors are grateful to Drs. Michael Maguire and Ruth Siegel for critical review of the manuscript. We would also like to thank Dr. Xing-Huang Gao for technical assistance. This work was supported in part by NIH Grant PO1 AG 15885 (J.J.M.) and a Department of Veterans Affairs Merit Review Grant (J.J.M.) and NIH Training Grants T32 GM008803 (EAS) and T32 DK007319 (E.A.S.).

\section{Reference List}

1. Riedlerer PF. Views on neurodegeneration as a basis for neuroprotective strategies. Med Sci Monit. 2004; 10(12):RA287-RA290. [PubMed: 15567992] 
2. Maguire-Zeiss KA, Short DW, Federoff HJ. Synuclein, dopamine and oxidative stress: coconspirators in Parkinson's disease? Brain Res Mol Brain Res. 2005; 134(1):18-23. [PubMed: 15790526]

3. Olanow CW, Tatton WG. Etiology and pathogenesis of Parkinson's disease. Annu Rev Neurosci. 1999; 22:123-144. [PubMed: 10202534]

4. Gandhi S, Wood NW. Molecular pathogenesis of Parkinson's disease. Hum Mol Genet. 2005; 14(Spec No. 2):2749-2755.

5. Walkinshaw G, Waters CM. Induction of apoptosis in catecholaminergic PC12 cells by L-DOPA. Implications for the treatment of Parkinson's disease. J Clin Invest. 1995; 95(6):2458-2464. [PubMed: 7769091]

6. Sabens EA, Distler AM, Mieyal JJ. Levodopa deactivates enzymes that regulate thiol-disulfide homeostasis and promotes neuronal cell death: implications for therapy of Parkinson's disease 1. Biochemistry. 2010; 49(12):2715-2724. [PubMed: 20141169]

7. Maruyama W, Oya-Ito T, Shamoto-Nagai M, Osawa T, Naoi M. Glyceraldehyde-3-phospate dehydrogenase is translocated into nuclei through Golgi apparatus during apoptosis induced by 6hydroxydopamine in human dopaminergic SH-SY5Y cells. Neurosci Lett. 2002; 321(1-2):29-32. [PubMed: 11872249]

8. Nunes C, Almeida L, Laranjinha J. 3,4-Dihydroxyphenylacetic acid (DOPAC) modulates the toxicity induced by nitric oxide in PC-12 cells via mitochondrial dysfunctioning. Neurotoxicology. 2008

9. Ouyang M, Shen X. Critical role of ASK1 in the 6-hydroxydopamine-induced apoptosis in human neuroblastoma SH-SY5Y cells. J Neurochem. 2006; 97(1):234-244. [PubMed: 16515547]

10. Pan J, Zhao YX, Wang ZQ, Jin L, Sun ZK, Chen SD. Expression of FasL and its interaction with Fas are mediated by c-Jun N-terminal kinase (JNK) pathway in 6-OHDA-induced rat model of Parkinson disease 9. Neurosci Lett. 2007; 428(2-3):82-87. [PubMed: 17959308]

11. Panet H, Barzilai A, Daily D, Melamed E, Offen D. Activation of nuclear transcription factor kappa B (NF-kappaB) is essential for dopamine-induced apoptosis in PC12 cells. J Neurochem. 2001; 77(2):391-398. [PubMed: 11299301]

12. Hao C, March RE, Croley TR, Chen S, Legault MG, Yang P. Study of the neurotransmitter dopamine and the neurotoxin 6-hydroxydopamine by electrospray ionization coupled with tandem mass spectrometry 1. Rapid Commun Mass Spectrom. 2002; 16(6):591-599. [PubMed: 11870897]

13. Sabens, EA.; Mieyal, JJ. Glutaredoxin and Thioredoxin Enzyme Systems: Catalytic Mechanisms and Physiological Functions. In: Masella, R.; M, G., editors. Glutathione and Sulfer Amino Acids in Human Health and Disease. John Wiley and Sons, Inc.; Hoboken, New Jersey: 2009. p. 121-156.

14. Nordberg J, Arner ES. Reactive oxygen species, antioxidants, and the mammalian thioredoxin system. Free Radic Biol Med. 2001; 31(11):1287-1312. [PubMed: 11728801]

15. Nakamura H, Nakamura K, Yodoi J. Redox regulation of cellular activation. Annu Rev Immunol. 1997; 15:351-369. [PubMed: 9143692]

16. Shelton MD, Distler AM, Kern TS, Mieyal JJ. Glutaredoxin Regulates Autocrine and Paracrine Proinflammatory Responses in Retinal Glial (Muller) Cells. J Biol Chem. 2009; 284(8):47604766. [PubMed: 19074435]

17. Ghosh A, Roy A, Liu X, Kordower JH, Mufson EJ, Hartley DM, Ghosh S, Mosley RL, Gendelman HE, Pahan K. Selective inhibition of NF-kappaB activation prevents dopaminergic neuronal loss in a mouse model of Parkinson's disease. Proc Natl Acad Sci U S A. 2007; 104(47):18754-18759. [PubMed: 18000063]

18. Tarabin V, Schwaninger M. The role of NF-kappaB in 6-hydroxydopamine- and TNFalphainduced apoptosis of PC12 cells. Naunyn Schmiedebergs Arch Pharmacol. 2004; 369(6):563-569. [PubMed: 15141332]

19. Lee HJ, Kim SH, Kim KW, Um JH, Lee HW, Chung BS, Kang CD. Antiapoptotic role of NFkappaB in the auto-oxidized dopamine-induced apoptosis of PC12 cells. J Neurochem. 2001; 76(2):602-609. [PubMed: 11208923] 
20. Matsuzawa A, Ichijo H. Redox control of cell fate by MAP kinase: physiological roles of ASK1MAP kinase pathway in stress signaling 6. Biochim Biophys Acta. 2008; 1780(11):1325-1336. [PubMed: 18206122]

21. Niso-Santano M, Gonzalez-Polo RA, Bravo-San Pedro JM, Gomez-Sanchez R, Lastres-Becker I, Ortiz-Ortiz MA, Soler G, Moran JM, Cuadrado A, Fuentes JM. Activation of apoptosis signalregulating kinase 1 is a key factor in paraquat-induced cell death: Modulation by the Nrf2/Trx axis 1. Free Radic Biol Med. 2010:1370-1381. [PubMed: 20202476]

22. Karunakaran S, Diwakar L, Saeed U, Agarwal V, Ramakrishnan S, Iyengar S, Ravindranath V. Activation of apoptosis signal regulating kinase 1 (ASK1) and translocation of death-associated protein, Daxx, in substantia nigra pars compacta in a mouse model of Parkinson's disease: protection by alpha-lipoic acid. FASEB J. 2007; 21(9):2226-2236. [PubMed: 17369508]

23. Saeed U, Durgadoss L, Valli RK, Joshi DC, Joshi PG, Ravindranath V. Knockdown of cytosolic glutaredoxin 1 leads to loss of mitochondrial membrane potential: implication in neurodegenerative diseases. PLoS ONE. 2008; 3(6):e2459. [PubMed: 18560520]

24. Yang W, Tiffany-Castiglioni E, Koh HC, Son IH. Paraquat activates the IRE1/ASK1/JNK cascade associated with apoptosis in human neuroblastoma SH-SY5Y cells 1. Toxicol Lett. 2009; 191(2-3):203-210. [PubMed: 19735704]

25. Onyango IG, Tuttle JB, Bennett JP Jr. Activation of p38 and N-acetylcysteine-sensitive c-Jun NH2-terminal kinase signaling cascades is required for induction of apoptosis in Parkinson's disease cybrids. Mol Cell Neurosci. 2005; 28(3):452-461. [PubMed: 15737736]

26. Harper SJ, Wilkie N. MAPKs: new targets for neurodegeneration 1. Expert Opin Ther Targets. 2003; 7(2):187-200. [PubMed: 12667097]

27. Miloso M, Scuteri A, Foudah D, Tredici G. MAPKs as mediators of cell fate determination: an approach to neurodegenerative diseases. Curr Med Chem. 2008; 15(6):538-548. [PubMed: 18336268]

28. Klegeris A, McGeer PL. R-(-)-Deprenyl inhibits monocytic THP-1 cell neurotoxicity independently of monoamine oxidase inhibition. Exp Neurol. 2000; 166(2):458-464. [PubMed: 11085911]

29. McGeer PL, Itagaki S, Boyes BE, McGeer EG. Reactive microglia are positive for HLA-DR in the substantia nigra of Parkinson's and Alzheimer's disease brains 1. Neurology. 1988; 38(8):12851291. [PubMed: 3399080]

30. Legros H, Dingeval MG, Janin F, Costentin J, Bonnet JJ. Toxicity of a treatment associating dopamine and disulfiram for catecholaminergic neuroblastoma SH-SY5Y cells: relationships with 3,4-dihydroxyphenylacetaldehyde formation. Neurotoxicology. 2004; 25(3):365-375. [PubMed: 15019299]

31. Qanungo S, Starke DW, Pai HV, Mieyal JJ, Nieminen AL. Glutathione supplementation potentiates hypoxic apoptosis by S-glutathionylation of p65-NFkappaB. J Biol Chem. 2007; 282(25):18427-18436. [PubMed: 17468103]

32. Song JJ, Lee YJ. Differential role of glutaredoxin and thioredoxin in metabolic oxidative stressinduced activation of apoptosis signal-regulating kinase 1. Biochem J. 2003; 373(Pt 3):845-853. [PubMed: 12723971]

33. Saitoh M, Nishitoh H, Fujii M, Takeda K, Tobiume K, Sawada Y, Kawabata M, Miyazono K, Ichijo H. Mammalian thioredoxin is a direct inhibitor of apoptosis signal-regulating kinase (ASK) 1. EMBO J. 1998; 17(9):2596-2606. [PubMed: 9564042]

34. Keshet Y, Seger R. The MAP kinase signaling cascades: a system of hundreds of components regulates a diverse array of physiological functions 1. Methods Mol Biol. 2010; 661:3-38. [PubMed: 20811974]

35. Mathiasen JR, McKenna BA, Saporito MS, Ghadge GD, Roos RP, Holskin BP, Wu ZL, Trusko SP, Connors TC, Maroney AC, Thomas BA, Thomas JC, Bozyczko-Coyne D. Inhibition of mixed lineage kinase 3 attenuates MPP+-induced neurotoxicity in SH-SY5Y cells 3. Brain Res. 2004; 1003(1-2):86-97. [PubMed: 15019567]

36. Levy OA, Malagelada C, Greene LA. Cell death pathways in Parkinson's disease: proximal triggers, distal effectors, and final steps 1. Apoptosis. 2009; 14(4):478-500. [PubMed: 19165601] 
37. Maroney AC, Finn JP, Connors TJ, Durkin JT, Angeles T, Gessner G, Xu Z, Meyer SL, Savage MJ, Greene LA, Scott RW, Vaught JL. Cep-1347 (KT7515), a semisynthetic inhibitor of the mixed lineage kinase family 2. J Biol Chem. 2001; 276(27):25302-25308. [PubMed: 11325962]

38. Cross JV, Templeton DJ. Oxidative stress inhibits MEKK1 by site-specific glutathionylation in the ATP-binding domain. Biochem J. 2004; 381(Pt 3):675-683. [PubMed: 15139849]

39. Nadeau PJ, Charette SJ, Landry J. REDOX reaction at ASK1-Cys250 is essential for activation of JNK and induction of apoptosis 43. Mol Biol Cell. 2009; 20(16):3628-3637. [PubMed: 19570911]

40. Goldman EH, Chen L, Fu H. Activation of apoptosis signal-regulating kinase 1 by reactive oxygen species through dephosphorylation at serine 967 and 14-3-3 dissociation 3. J Biol Chem. 2004; 279(11):10442-10449. [PubMed: 14688258]

41. Kim AH, Khursigara G, Sun X, Franke TF, Chao MV. Akt phosphorylates and negatively regulates apoptosis signal-regulating kinase 1 95. Mol Cell Biol. 2001; 21(3):893-901. [PubMed: 11154276]

42. Park HS, Cho SG, Kim CK, Hwang HS, Noh KT, Kim MS, Huh SH, Kim MJ, Ryoo K, Kim EK, Kang WJ, Lee JS, Seo JS, Ko YG, Kim S, Choi EJ. Heat shock protein hsp72 is a negative regulator of apoptosis signal-regulating kinase 1 3. Mol Cell Biol. 2002; 22(22):7721-7730. [PubMed: 12391142]

43. Zhang R, Luo D, Miao R, Bai L, Ge Q, Sessa WC, Min W. Hsp90-Akt phosphorylates ASK1 and inhibits ASK1-mediated apoptosis 1. Oncogene. 2005; 24(24):3954-3963. [PubMed: 15782121]

44. Carbone DL, Doorn JA, Kiebler Z, Sampey BP, Petersen DR. Inhibition of Hsp72-mediated protein refolding by 4-hydroxy-2-nonenal 1. Chem Res Toxicol. 2004; 17(11):1459-1467. [PubMed: 15540944]

45. Martinez-Ruiz A, Villanueva L, Gonzalez de OC, Lopez-Ferrer D, Higueras MA, Tarin C, Rodriguez-Crespo I, Vazquez J, Lamas S. S-nitrosylation of Hsp90 promotes the inhibition of its ATPase and endothelial nitric oxide synthase regulatory activities 45. Proc Natl Acad Sci U S A. 2005; 102(24):8525-8530. [PubMed: 15937123]

46. Kim SY, Kim TJ, Lee KY. A novel function of peroxiredoxin 1 (Prx-1) in apoptosis signalregulating kinase 1 (ASK1)-mediated signaling pathway. FEBS Lett. 2008; 582(13):1913-1918. [PubMed: 18501712]

47. Lee YM, Park SH, Shin DI, Hwang JY, Park B, Park YJ, Lee TH, Chae HZ, Jin BK, Oh TH, Oh YJ. Oxidative modification of peroxiredoxin is associated with drug-induced apoptotic signaling in experimental models of Parkinson disease 125. J Biol Chem. 2008; 283(15):9986-9998. [PubMed: 18250162]

48. Waak J, Weber SS, Gorner K, Schall C, Ichijo H, Stehle T, Kahle PJ. Oxidizable residues mediating protein stability and cytoprotective interaction of DJ-1 with apoptosis signal-regulating kinase 1 2. J Biol Chem. 2009; 284(21):14245-14257. [PubMed: 19293155]

49. Mo JS, Jung J, Yoon JH, Hong JA, Kim MY, Ann EJ, Seo MS, Choi YH, Park HS. DJ-1 modulates the p38 mitogen-activated protein kinase pathway through physical interaction with apoptosis signal-regulating kinase 1 1. J Cell Biochem. 2010; 110(1):229-237. [PubMed: 20213747]

50. Saeed U, Ray A, Valli RK, Kumar AM, Ravindranath V. DJ-1 Loss by Glutaredoxin But Not Glutathione Depletion Triggers Daxx Translocation and Cell Death 1. Antioxid Redox Signal. 2010; 13(2):127-144. [PubMed: 20014998]

51. Kim SD, Moon CK, Eun SY, Ryu PD, Jo SA. Identification of ASK1, MKK4, JNK, c-Jun, and caspase-3 as a signaling cascade involved in cadmium-induced neuronal cell apoptosis 23. Biochem Biophys Res Commun. 2005; 328(1):326-334. [PubMed: 15670787]

52. Chrestensen CA, Starke DW, Mieyal JJ. Acute cadmium exposure inactivates thioltransferase (Glutaredoxin), inhibits intracellular reduction of protein-glutathionyl-mixed disulfides, and initiates apoptosis. J Biol Chem. 2000; 275(34):26556-26565. [PubMed: 10854441]

53. Cassarino DS, Halvorsen EM, Swerdlow RH, Abramova NN, Parker WD Jr, Sturgill TW, Bennett JP Jr. Interaction among mitochondria, mitogen-activated protein kinases, and nuclear factorkappaB in cellular models of Parkinson's disease 3. J Neurochem. 2000; 74(4):1384-1392. [PubMed: 10737593] 
54. Hunot S, Vila M, Teismann P, Davis RJ, Hirsch EC, Przedborski S, Rakic P, Flavell RA. JNKmediated induction of cyclooxygenase 2 is required for neurodegeneration in a mouse model of Parkinson's disease 1. Proc Natl Acad Sci U S A. 2004; 101(2):665-670. [PubMed: 14704277]

55. Ferrer I, Blanco R, Carmona M, Puig B, Barrachina M, Gomez C, Ambrosio S. Active, phosphorylation-dependent mitogen-activated protein kinase (MAPK/ERK), stress-activated protein kinase/c-Jun N-terminal kinase (SAPK/JNK), and p38 kinase expression in Parkinson's disease and Dementia with Lewy bodies 1. J Neural Transm. 2001; 108(12):1383-1396. [PubMed: 11810403]

56. The Parkinson Study Group PRECEPT Investigators. Mixed lineage kinase inhibitor CEP-1347 fails to delay disability in early Parkinson disease 1. Neurology. 2007; 69(15):1480-1490. [PubMed: 17881719]

57. Mielke K, Damm A, Yang DD, Herdegen T. Selective expression of JNK isoforms and stressspecific JNK activity in different neural cell lines. Brain Res Mol Brain Res. 2000; 75(1):128-137. [PubMed: 10648896]

\section{Abbreviations}

$\mathbf{A} \boldsymbol{\beta}$

ASK1

ATCC

$\operatorname{Daxx}$

DJ-1

L-DOPA

EDTA

Grx1

GSH

GSSG

HSP

6-OHDA

ІкB

IKK

JNK

LNCaP

MAPK

MAPKKK

MEKK

MLK

MN9D

MPTP

MTT

NADPH amyloid beta protein

apoptosis signaling kinase 1

American Type Culture Collection

Death associated protein 6

a protein implicated in Parkinson's disease that functions as an antioxidant, transcriptional co-activator, and molecular chaperone

L-3,4-dihydroxyphenylalanine

ethylene diamine tetraacetic acid

Glutaredoxin

glutathione

glutathione disulfide

heat shock protein

6-hydroxydopamine

I Kappa B

I Kappa B Kinase

cJun $\mathrm{N}$ terminal kinase

lymph node prostate carcinoma cells

mitogen activated protein kinase

mitogen activated protein kinase kinase kinase

mitogen activated protein kinase kinase

mixed lineage kinase

murine mesencephalic neurons 9D

1-methyl-4-phenyl-1,2,3,6-tetrahydropyridine

[4,5-dimethylthiazol-2-yl]-2,5-diphenyl tetrazolium bromide

nicotinamide adenine dinucleotide phosphate 


$\begin{array}{ll}\text { NFкB } & \text { Nuclear Factor-Kappa-B } \\ \text { p38 } & \text { p38 MAPK } \\ \text { PBS } & \text { phosphate buffered saline } \\ \text { PD } & \text { Parkinson's disease } \\ \text { ROS } & \text { reactive oxygen species } \\ \text { SHSY5Y } & \begin{array}{l}\text { immortalized cells obtained from human bone marrow neuroblastoma which } \\ \text { display typical dompamineric characteristics; for simplicity these cells are }\end{array} \\ & \text { referred to as "SHSY5Y neurons." } \\ \text { Trx1 } & \text { Thioredoxin }\end{array}$




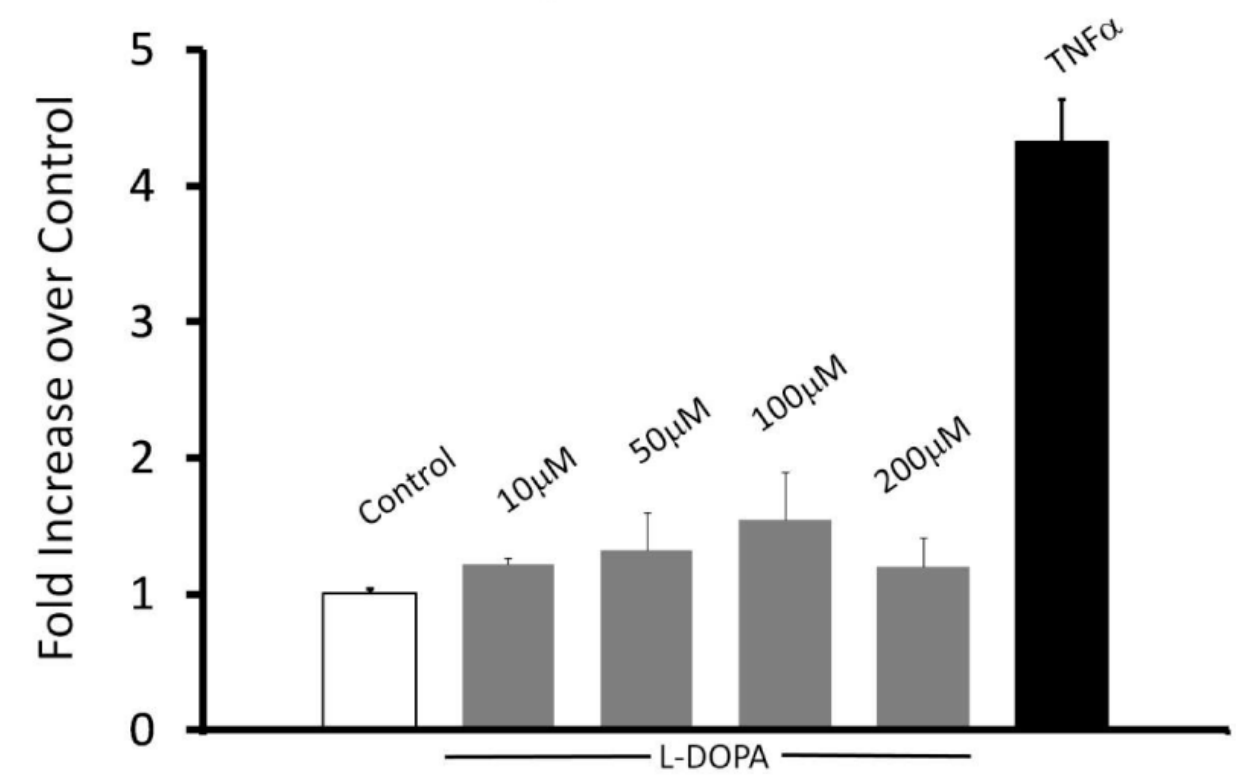

Figure 1. NFкB Transcriptional Activity is not affected by L-DOPA Treatment of SHSY5Y Cells Bar graph representing NFkkB luciferase activity relative to Renilla luciferase activity, which served as the measure of transfection efficiency in each case. Values are represented as fold over control, with the control normalized to 1 (white bar). L-DOPA (gray bars) or $\mathrm{TNF} \alpha(50 \mathrm{ng} / \mathrm{mL}$, used as a positive control, black bar) were added $24 \mathrm{hr}$ post transfection. Samples were analyzed $24 \mathrm{hr}$ after treatment. $\mathrm{n}=3$. Three separate preparations of cells were treated and analyzed for each condition, and the analysis of each set of cells was done at least two times. 


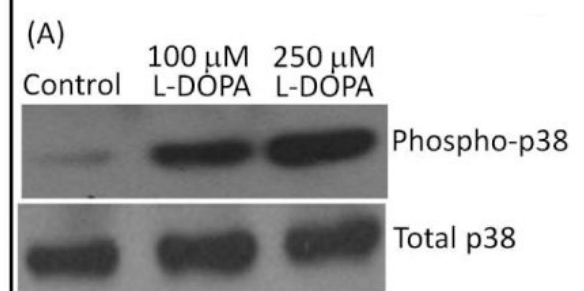

(B)

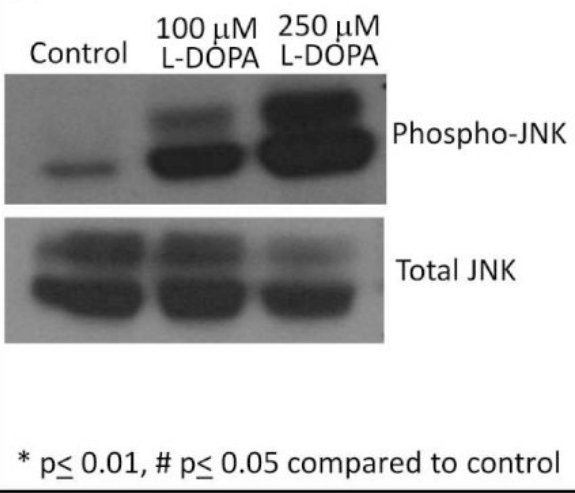

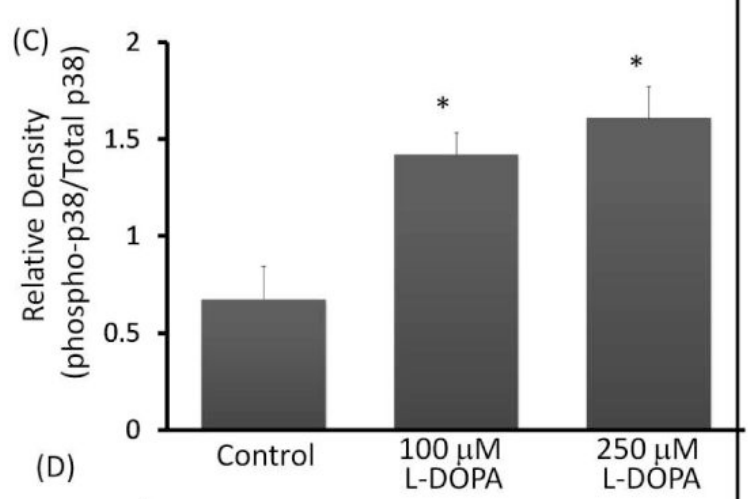

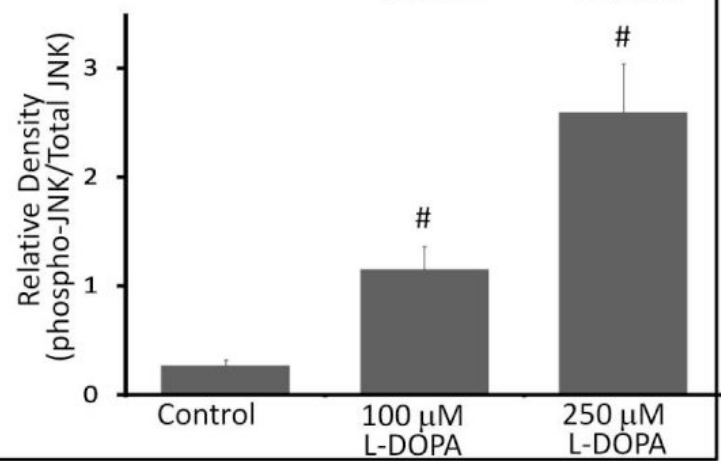

Figure 2. Increased Phosphorylation of p38 and JNK occurs with L-DOPA Treatment of SHSY5Y Cells

(A) Representative western blot showing increased phoshorylation of p38. SHSY5Y cells were treated for $24 \mathrm{hr}$ with the indicated concentrations of L-DOPA, and control cells were incubated in parallel. (B) Representative western blot showing increased phoshorylation of JNK. SHSY5Y cells were treated for $24 \mathrm{hr}$ with the indicated concentrations of L-DOPA, and control cells were incubated in parallel. Two bands are observed for JNK, representing the isoforms present within SHSY5Y cells (57). (C) Bar graph displaying quantification of multiple western blots measuring phosphorylation of $\mathrm{p} 38$. Each was quantified by densitometry and normalized to total $\mathrm{p} 38$, which was developed and quantified on the same western blot. $\mathrm{n}=4$. ${ }^{*} \mathrm{p}<0.01$ compared to control. ( $\mathrm{p}=18$ for $250 \mu \mathrm{M}$ compared to $100 \mu \mathrm{M}$ ) (D) Bar graph displaying quantification of western blots measuring phosphorylation of JNK. Both isoforms were quantified and added to yield results in the bar graph. Each was normalized to total protein. $\mathrm{n}=4$. \# $\mathrm{p}<0.05$ compared to control. $(\mathrm{p}=.03$ for $250 \mu \mathrm{M}$ compared to $100 \mu \mathrm{M})$. 


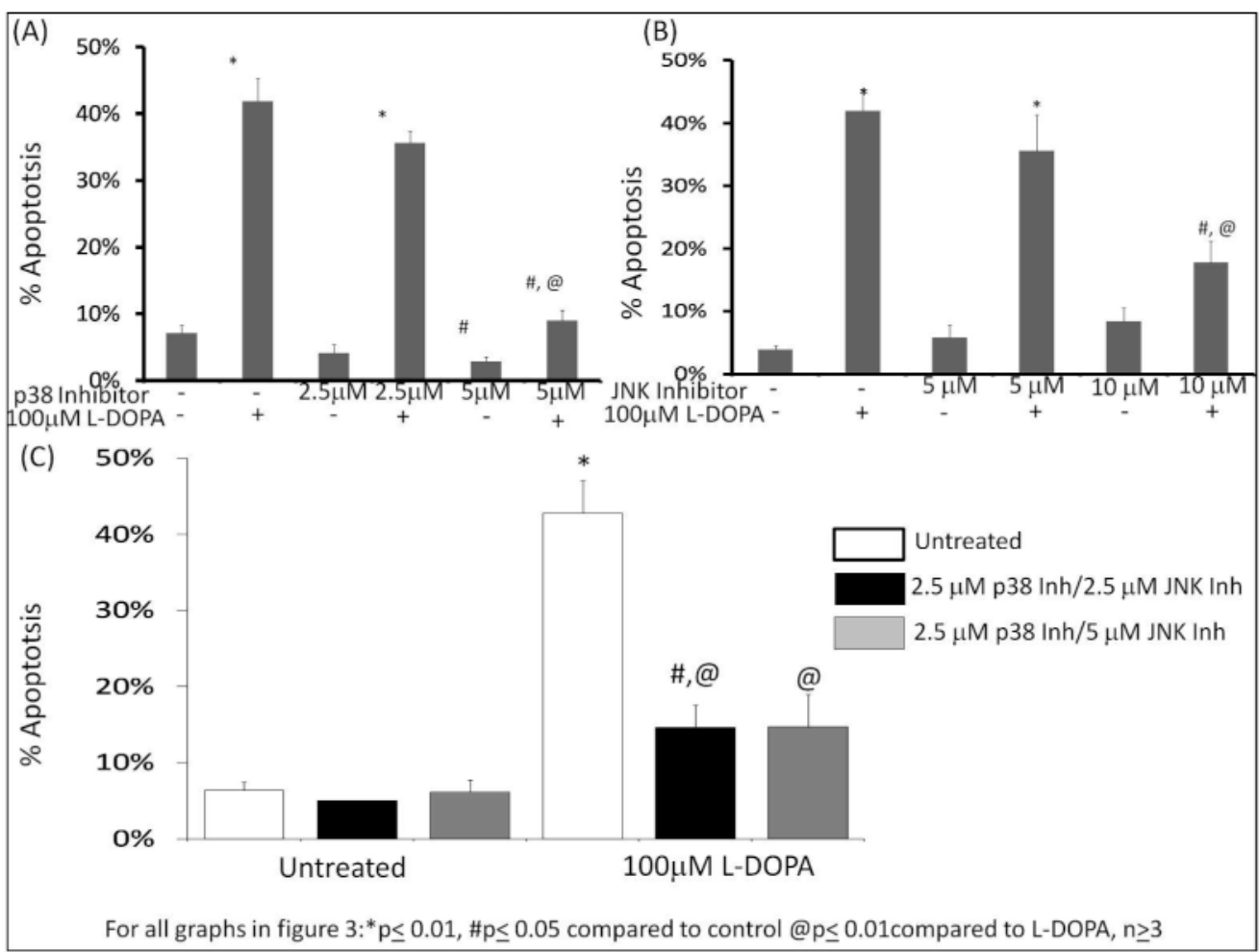

Figure 3. MAPK Inhibition Leads to Decreased Apoptosis in L-DOPA treated SHSY5Y Cells, where p38 and JNK inhibitors function synergistically

(A) Bar graph representing quantification of SHSY5Y cells for chromatin condensation following $24 \mathrm{hr}$ L-DOPA treatment, plus or minus p38 inhibitor. Cells were treated $30 \mathrm{~min}$ prior to L-DOPA with p38 inhibitor (SB202190) or DMSO (vehicle). $n=3$. Three separate preparations of cells were treated and analyzed for each condition, and the analysis of each set of cells was done three times. \# represents $\mathrm{p}<0.05$ compared to control, $* \mathrm{p}<0.01$ compared to control, @ $\mathrm{p}<0.01$ compared to L-DOPA. (B) Bar graph representing chromatin condensation of SHSY5Y cells following $24 \mathrm{hr}$ L-DOPA treatment, plus or minus JNK inhibitor. Cells were treated 30 min prior to L-DOPA with $10 \mu \mathrm{M}$ JNK Inhibitor (SP600125) or DMSO (vehicle). $n=3$. Three separate preparations of cells were treated and analyzed for each condition, and the analysis of each set of cells was done three times. \# represents $\mathrm{p}<0.05$ compared to control, * represents $\mathrm{p}<0.01$ compared to control, @ $\mathrm{p}<0.01$ compared to L-DOPA. (C) Bar graph representing quantification of SHSY5Y cells for chromatin condensation following $24 \mathrm{hr}$ L-DOPA treatment, plus or minus combinations of p38 and JNK inhibitors. White bars represent samples without inhibitor treatment, light gray bars represent samples treated with $2.5 \mu \mathrm{M}$ p38 inhibitor and $2.5 \mu \mathrm{M}$ JNK inhibitor, and black bars represent samples treated with $2.5 \mu \mathrm{M}$ p38 inhibitor and $5 \mu \mathrm{M}$ JNK inhibitor. Samples were counted in a blinded fashion. Three separate preparations of cells were treated and analyzed for each condition, and the analysis of each set of cells was done three times. * represents $\mathrm{p}<0.01$ compared to control, @ $\mathrm{p}<0.01$ compared to L-DOPA. 


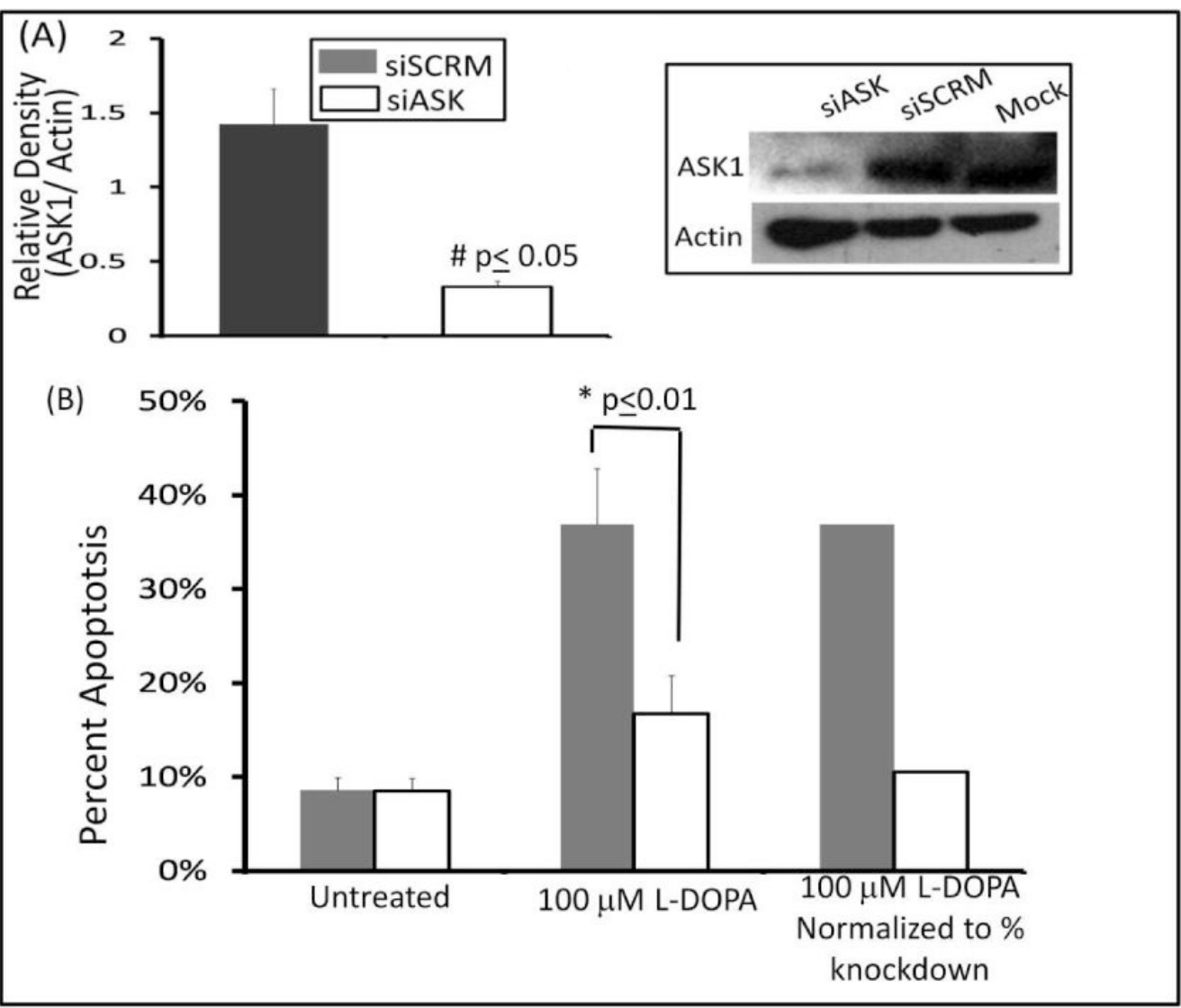

Figure 4. Knockdown of ASK1 Prevents L-DOPA induced Apoptosis

(A) Bar graph quantifying ASK1 knockdown in SHSY5Y cells after treatment with siRNA for $24 \mathrm{hr}$, normalized to the actin loading control. The difference is significant at $\mathrm{p}<0.05$ $(n=3)$. Knockdown of ASK1 was measured by western blot analysis prior to L-DOPA treatment (representative blot shown in inset.). ASK1 remained knocked down after LDOPA treatment (data not shown). (B) Bar graph showing quantification of percent apoptosis $(n=4)$. Four separate preparations of cells were treated and analyzed for each condition, and the analysis of each set of cells was done three times. The set of bars at the far right display percent apoptosis normalized to the percent knockdown of ASK1 observed by western blot. 


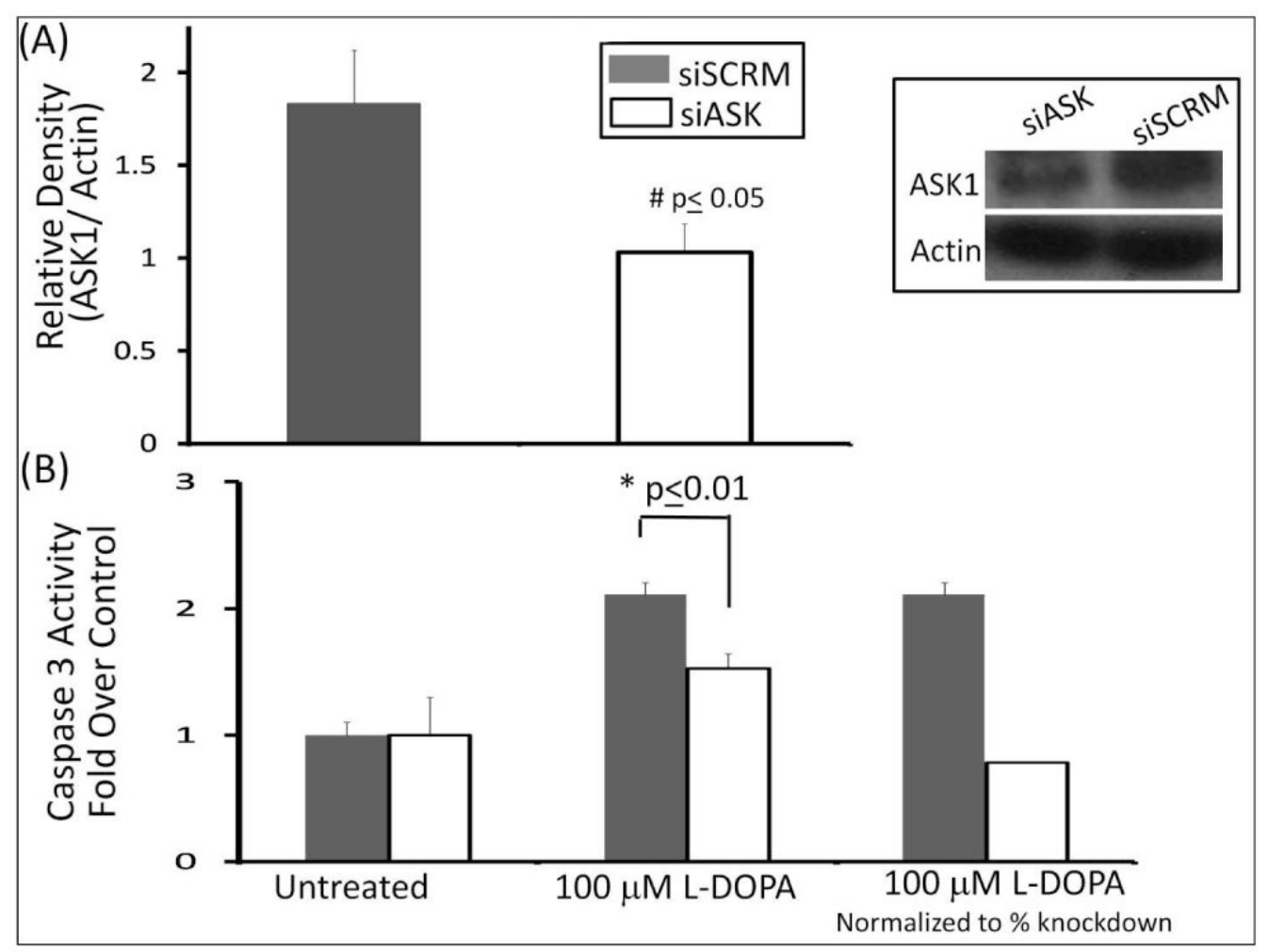

Figure 5. Caspase 3 Activity is Diminished with ASK1 knockdown

(A) Bar graph quantifying ASK1 knockdown in SHSY5Y cells after treatment with siRNA for $24 \mathrm{hr}$, normalized to the actin loading control. The difference is significant at $\mathrm{p}<0.05$ $(n=3)$. Knockdown of ASK1 was measured by western blot analysis prior to L-DOPA treatment (representative blot shown in inset.). The percent knockdown $(44 \% \pm 9 \%)$ was less than the observed knockdown for cells used in Figure 6; potentially due to the different preparation of siRNA that was used in this case (different manufacturer's lot number). (B) Bar graph quantifying caspase 3 activity after L-DOPA treatment in both scrambled control cells and ASK1 knockdown cells. Caspase 3 activity was measured fluorometrically and samples were normalized to nontreated and expressed as fold over nontreated. 6 separate preparations of cells were treated and analyzed for each condition. The difference was statistically significant with $\mathrm{p}=0.014$. The set of bars at the far right display change in caspase activity normalized to the percent knockdown of ASK1 observed by western blot. 


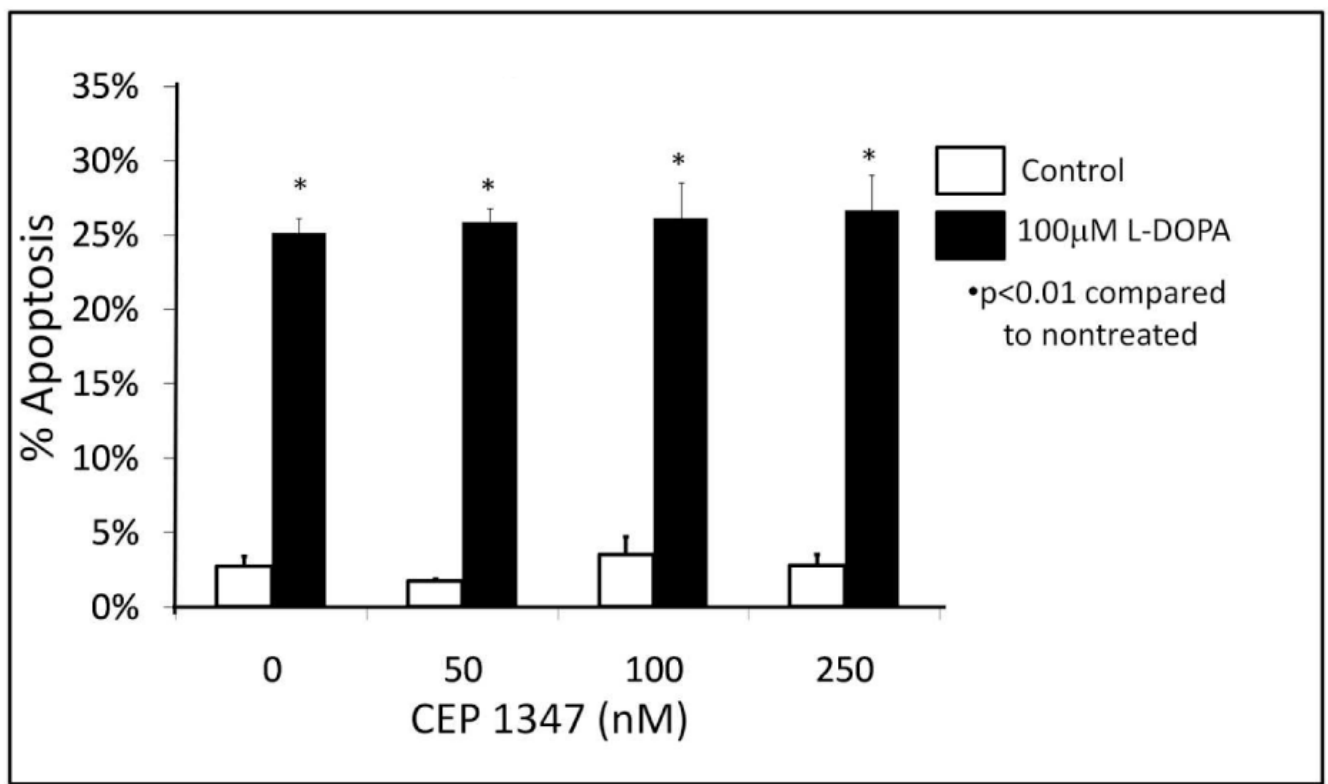

Figure 6. Inhibitor of MLK Does Not Prevent L-DOPA induced Apoptosis

Bar graph representing quantification of SHSY5Y cells for chromatin condensation (Hoechst staining) following $24 \mathrm{hr}$ L-DOPA treatment, plus or minus MLK inhibitor. The white bars represent vehicle treated cells and black bars represent cells treated with $100 \mu \mathrm{M}$ L-DOPA. All pretreatments with CEP 1347 were performed for $30 \mathrm{~min}$ prior to L-DOPA treatment. Apoptosis was assessed 24 hours after L-DOPA treatment. Bars represent 4 separate cell preparations, each counted three times. \# $\mathrm{p} \leq 0.05$, ${ }^{*} \mathrm{p} \leq 0.01$ compared to nontreated. 